\title{
ANALISIS KARAKTERISASI OP-AMP MENGGUNAKAN VIRTUAL INSTRUMENT
}

\author{
Romdhoni \\ Prodi Teknik Elektro UNPAM \\ JIn. Puspiptek Raya No 46 Buaran, Setu - Tangerang Selatan 15310 INDONESIA \\ Email: dosen00932@unpam.ac.id
}

\begin{abstract}
ABSTRAK
Alat pengukuran rangkaian op-amp yang ada di Lab Universitas Pamulang masih menggunakan sistem analog. Agar mahasiswa lebih mudah memahami dalam melakukan pengukuran maka di perlukan penelitian tentang analisis karakterisasi op-omp menggunakan Virtual Instrument. Oleh karena itu, tujuan penelitian ini adalah untuk mengetahui karakterisasi op-amp menggunakan Virtual Instrument dengan program LabView. Metode penelitian ini adalah membuat perangkat dengan hardware Ni My Daq menggunakan virtual instrument dan alat yang digunakan IC LM 741 sebagai penguat tegangan. Hasil penelitian diperoleh nilai input Vin 0.5 volt dengan resistensi beban Ri sebesar $10 \mathrm{~K} \Omega$, dan resistensi unpam balik Rf sebesar $100 \mathrm{~K} \Omega$ menghasilkan penguatan tegangan sebesar -3.98 volt. Dapat di simpulkan analisis karakterisasi op-amp menggunakan virtual instrument mudah digunakan untuk keperluan yang lebih luas sebagai alat praktikum yang dilakukan oleh mahasiswa.
\end{abstract}

Kata kunci : Rangkaian Op-Amp, NI My Daq, labview

\begin{abstract}
ANALISIS KARAKTERISASI OP-AMP MENGGUNAKAN VIRTUAL INSTRUMENT. The op-amp circuit measurement tools in Lab Pamulang University still use analog system. In order for students to more easily understand in doing the measurement, then in need of research on op-omp characterization analysis using Virtual Instrument. Therefore, the purpose of this research is to know the characterization of op-amp using Virtual Instrument with LabView program. This research method is to make device with Ni My Daq hardware using virtual instrument and tool used IC LM 741 as voltage amplifier. The result of this research is Vin 0.5 volt input value with $\mathrm{Ri}$ load resistance of $10 \mathrm{~K} \Omega$, and $\mathrm{Rf}$ reverse resistance of $100 \mathrm{~K} \Omega$ gives a voltage gain of -3.98 volts. It can be concluded that op-amp characterization analysis using virtual instrument is easy to use for wider purposes as a practicum tool performed by students.
\end{abstract}

Keywords: Inverting and Non Inverting Op-Amp Series, NI My Daq, labview 


\section{PENDAHULUAN}

Kemajuan teknologi dibidang elektronik berkembang begitu pesat, sehingga berpengaruh dalam pembuatan suatu peralatan elektronik, khusus nya dalam pembuatan alat-alat pratikum rangkain op-amp. Sehingga berkembanglah alatalat canggih baik dari segi hardware dan software yang satu sama lain saling berkaitan dan saling mendukung, sehingga terciptalah suatu peralatan yang mudah dimengerti dan mudah digunakan. Sekarang ini masih banyak alat-alat praktikum, baik untuk pengukuran atau pengambilan data secara konvesional, yang kita sering lihat di masyarakat masih menggunakan system analog sehingga dalam keakuratannya masih kurang maksimal dalam pengukuran.

Oleh karena itu tujuan dalam praktikum dasar elektronik, yaitu rangkain Op-Amp dimana rangkaian tersebut banyak digunakan dalam perangkat elektronik, tetapi kurang mengetahui seberapa besar ke akuratan yang di analisa pada rangkain Op-Amp tersebut. Maka dengan permasalahan yang dihadapi untuk praktikum tersebut penulis merancang rangkaian Op-Amp menggunakan virtual instrument, dimana pada virtual instrument ini dapat mengetahui seberapa besar penyimpangan dalam pengukuran,bahkan hasilnya bisa disimpan dalam bentuk file. Virtual instrument hanya menggunakan beberapa perangkat diantaranya: media pengukuran yaitu sebuah alat praktikum, MyDAQ dan PC/komputer yang didalamnya sudah di lengkapi software LabView, sehingga dalam melakukan praktikum lebih mudah memahami hasil dari pengukuran, dan memudahkan dalam pengambilan data.

Praktikum menggunakan virtual instrument yang terdiri dari LabView dan NI $M y D A Q$ masih jarang digunakan di Indonesia,
LabView ini merupakan sebuah software pemograman yang diproduksi oleh National Instrument dengan konsep berbeda. LabView ini pemogramannya menggunakan pemograman berbasis grafis. NI MyDAQ merupakan suatu perangkat akuisisi data yang memberikan kemudahan untuk menganalisis rangkain opamp. NI MyDAQ sangat portabel sehingga dapat digunakan di ruang laboratorium UNPAM (univertitas Pamulamg) dan alat-alat standart industri, bahkan di lingkungan pelajar khususnya didunia pendidikan untuk digunakan sebagai alat praktikum, sehingga para pelajar lebih mudah mengenal dan mahir dalam menggunakan virtual instrument.

\section{LANDASAN TEORI}

Op-Amp adalah solid - state yang mampu mengindra dan memperkuat sinyal masukan baik DC maupun AC. Op-Amp yang khas terdiri dari tiga rangkaian dasar, yakni kuat diferensial impedansi masukan tinggi,dan penguat keluaran impedansi rendah (biasanya penguatan emitter push-pull). Lazimnya Op-Amp memelukan catu daya positif dan catu daya negatif. Karena catu daya demikian, tegangan keluaran dapat berayun positif dan negative terhadap bumi. Karakteristik op-amp yang terpenting adalah :

1. Impedansi masukan amat rendah, tinggi sehingga arus masukan praktis dapat diabaikan.

2. Penguat lup amat tinggi.

3. Impedansi keluaran amat rendah, sehingga keluaran penguat tidak dipengaruh oleh pembebanan.

Simbol op-amp standar dinyatakan dengan sebuah segi tiga, seperti tampak pada gambar 2.1. Terminal-terminal masukan ada pada bagian atas segitiga. Masukan pembalik dinyatakan 
dengan tanda minus (-). Tegangan DC atau AC yang dikenakan pada masukan ini akan digeser fasanya $180^{\circ}$ pada keluaran. Masukan tak pembalik dinyatakan pada masukan tanda plus (+). Teggangan DC atau AC pada masukan ini akan sefasa dengan keluarannya. Terminal keluaran diperhatikan pada sisi atas segitiga. Terminal-terminal catu daya dan kaki-kaki lainnya untuk kompensasi frekuensi atau pengaturan nol diperhatikan pada sisi atas dan sisi bawah segitiga. Tipe op-amp atau nomor produk berada di tengah-tengah segitiga. Rangkaian umum yang bukan menunjukan op-amp khusus memiliki simbol-simbol A1, A2 dan seterusnya. Atau Op1, OP2 dan seterusnya.

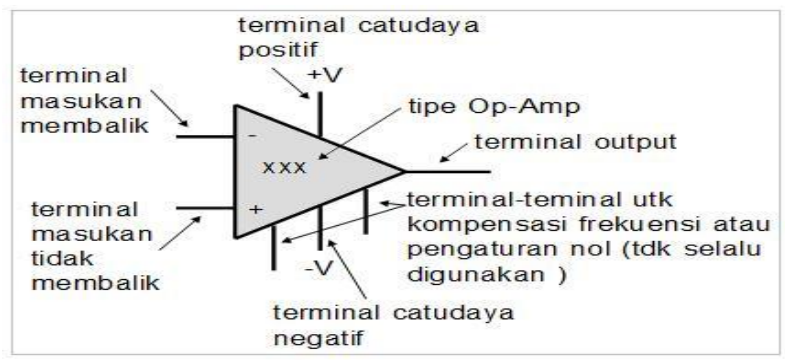

Gambar 1. Simbol Skematik Op-Amp Standar

Meskipun kita dapat mengunakan op-amp tanpa mengetahui secara tepat apa yang terjadi didalamnya, tetapi akan lebih baik bila karakteristik kerjanya kita pahami dengan mempelajari rangkaian internalnya. Gambar 2.3 menunjukan diagram skematiuk IC op-amp 741 yang populer. Op-amp lainnya tak berbeda. Resistor dan kapasitor diusahakan sesedikit mungkin dalam perancangan IC ini dan kalau mungkin digunakan transistor. Kapasitor kopling tidak di pakai di sini sehingga rangkaian dapat memperkuat sinyal DC sebagaimana sinyal pada AC.kapasitor $30 \quad \mathrm{pF}$ yang diperlihatkan memberikan kompentasi frekuensi internal. Opamp pada dasarnya terdiri atas tiga tahap: penguat diferensial impedansi masukan tinggi, penguat tegangan beberapa tegangan tinggi dengan penggeser level (sehingga keluaran dapat berayun positif atau negative), dan penguat keluaran impedansi rendah.

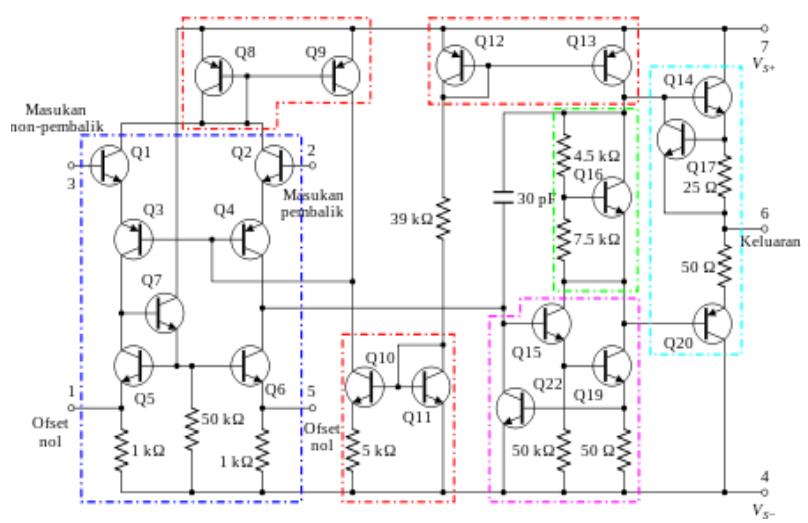

Gambar 2. diagram Stematik Op-Amp

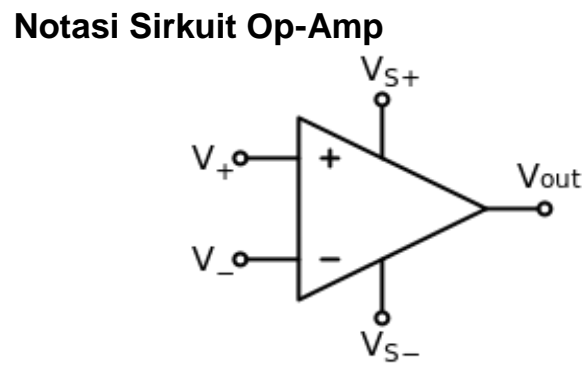

Gamabar 3. Notasi Sirkuit Op-Amp.

Simbol penguat operasional pada rangkaian seperti pada gambar di samping, di mana:

- $V_{+}$: masukan non-pembalik

- $V_{\text {_: }}$ masukan pembalik

- $V_{\text {out: keluaran }}$

- $V_{\mathrm{S}+\text { : catu daya positif }}$

- $V_{\mathrm{S}-\text { : catu daya negative }}$

Catu daya pada notasi penguat operasional sering kali tidak dicantumkan untuk memudahkan penggambaran rangkaian. 


\section{Penguat Pembalik (Inverting)}

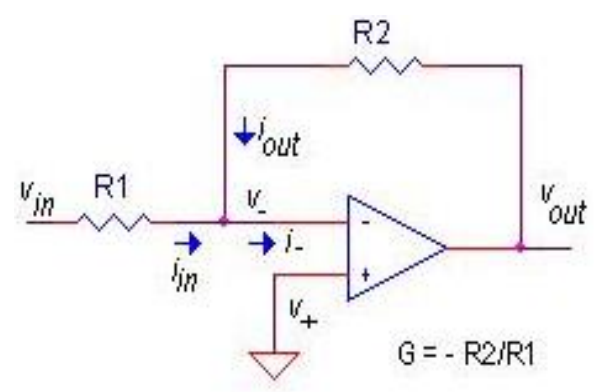

Gamba 4. Op-Amp Penguat Pembalik.

Sebuah penguat pembalik menggunakan umpan balik negatif untuk membalik dan menguatkan sebuah tegangan. Resistor $R_{f}$ melewatkan sebagian sinyal keluaran kembali kemasukan. Karena keluaran taksefase sebesar $180^{\circ}$, maka nilai keluaran tersebut secara efektif mengurangi besar masukan. Ini mengurangi bati keseluruhan dari penguat dan disebut dengan umpan balik negatif.

$$
V_{\text {out }}=-\frac{R_{\mathrm{f}}}{R_{\text {in }}} V_{\text {in }}
$$

Di mana,

$Z_{\text {in }}=R_{\text {in(karena }} V_{\text {_adalah bumi maya }}$ (virtual ground)

Sebuah resistor dengan nilai

$$
A=-\frac{R_{f}}{R_{\text {in }}}
$$

$R_{\mathrm{f}} \| R_{\mathrm{in}} \triangleq R_{\mathrm{f}} R_{\mathrm{in}} /\left(R_{\mathrm{f}}+R_{\mathrm{in}}\right)$,

ditempatkan di antara masukan non-pembalik dan bumi. Walaupun tidak dibutuhkan, hal ini mengurangi galat karena arus bias masukan. dari penguat ditentukan dari rasio antara $R_{f}$ dan $R_{i n}$, yaitu tanda negatif menunjukkan bahwa keluaran adalah pembalikan dari masukan. Contohnya jika $\mathrm{R}_{\mathrm{f}}$ adalah $10.000 \Omega, \mathrm{R}_{\text {in }}$ adalah $1.000 \Omega$, maka nilai bati adalah $-10.000 \Omega / 1.000 \Omega$, yaitu -10 .

\section{Penguat Tak Pembalik (Non Inverting).}

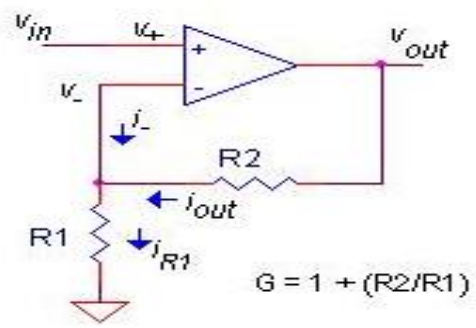

Gambar 5.Op-Amp Penguat Tak-Pembalik Rumus penguatan penguat non-pembalik adalah sebagai berikut:

$$
V_{\text {out }}=V_{\text {in }}\left(\frac{R_{1}+R_{2}}{R_{1}}\right)
$$

atau dengan kata lain:

$$
V_{\text {out }}=V_{\text {in }}\left(1+\frac{R_{2}}{R_{1}}\right)
$$

Dengan demikian, penguat non-pembalik memiliki bati minimum bernilai 1. Karena tegangan sinyal masukan terhubung langsung dengan masukan pada penguat operasional maka impedansi masukan bernilai $Z_{\text {in }} \approx \infty$.

\section{LabView}

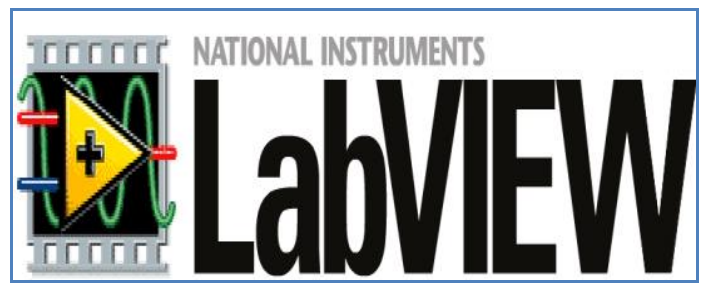

Gambar 6. Program Labview

LabView adalah sebuah software yang menpunyai pemograman yang diproduksi oleh Nasional instrument dengan konsep yang berbeda. seperti bahasa pemograman lainnya yaitu $\mathrm{C}++_{+}$, Matlab dan Visual basic. LabView juga mempunyai beberapa fungsi dan peranan yang sama, perbedaannya bahwa LabView menggunakan bahasa pemograman berbasis 
grafis atau blok diagram sementara bahasa pemograman lainnya menggunakan bahasa text.

Software LabView terdiri dari tiga komponen utama yaitu:

\section{Front panel.}

Front panel adalah bagian window yang berlatar belakang belakang abu-abu serta mengandung control dan indiktor. Front panel digunakan untuk membangun sebuah $\mathrm{VI}$, menjalankan program dan mendebug program.

\section{Control dan functions pallete}

Control dan functions pallete digunakan untuk membangun sebuah Vi. Control pallete merupakan tempat beberapa control dan indikator pada front panel, control palletehanya tersedia di front panel, untuk menampilkan contol pallete dapat dilakukan dengan mengklik windows show control pallete atau klik kanan pada front panel.

\section{NI MyDAQ.}

MyDAQ adalah suatu alat akuisisi data portable dengan biaya rendah, penggunaan perangkat MayDAQ menggunakan LabView sebagai basis softwarenya. MyDAQ dapat digunakan oleh para siswa untuk mengetahui cara mengukur dan menganalisis secara real suatu signal yang ada pada alam sekitarnya, MyDAQ dengan ukuran yang portable memungkinkan dalam pengukuran dan menganalisis dapat dilakukan dimana saja dan kapan saja, sehingga dengan mudah untuk digunakan.

Pada MyDAQ terdapat beberapa aksesoris yang dapat digunakan untuk mendukung dalam pengukuran dan analisis diantaranya:

1. Analog Input.

Ada dua saluran analog input pada MyDAQ, saluran ini dapat dikonfigurasikan baik sebagai impendance differensial tegangan input atau input audio, input analog multiplexing yang berarti satu analog kedigital converter(ADC) untuk digunakan sebagai sampel kedua saluran.

\section{Analog Output.}

Pada analog output ini menghasilkan sinyal \pm $10 \mathrm{~V}$ dalam bentuk mode audio dan dua saluran output yang mewakili stereo kiri dan kanan, keluaran analog dapat diperbaharui sampai dengan $200 \mathrm{kS} / \mathrm{s}$ per saluran. Keluaran analog dapat digunakan dalam ELVISmxfungsi generator dan bode instrument analyzer.

3. Digital input/Digital output.

Ada delapan line digital input/digital output(DIO) pada MyDAQ, setiap line adalah antar muka/interface fungsi diprogram (PFI) artinya dapat dikonfigurasi sebagai perangkat lunak untuk digital input dan digital output atau dapat bertindak sebagai fungsi masukan dan keluaran. Analog input/Analog output dan Digital input/Digital output dapat dilihat pada gambar dibawah ini :

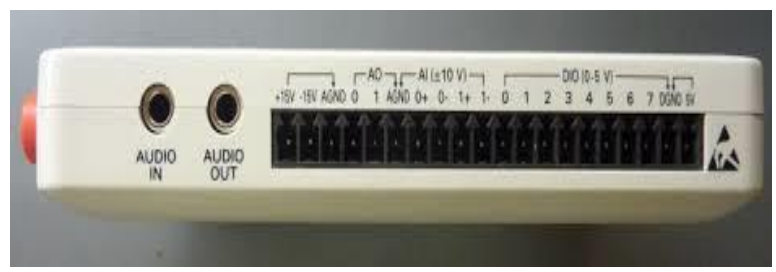

Gambar 7. Analog input/output dan Digital input/output.

\section{Catu daya.}

Ada tiga masukan energi listrik yang tersedia untuk digunakan pada MyDAQ, +15V dan -15V dapat digunakan untuk komponen analog seperti penguat operasional dan regulator linear. 


\section{METODOLOGI PENELITIAN.}

Perancangan alat ini mempunyai tujuan, yaitu untuk mendapatkan suatu alat pratikum yang sistematis dan mudah untuk di pahami.

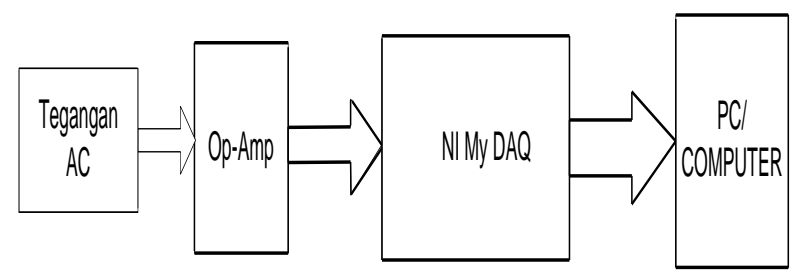

Diagram Blok Alat Ukur

Diagram Alir.

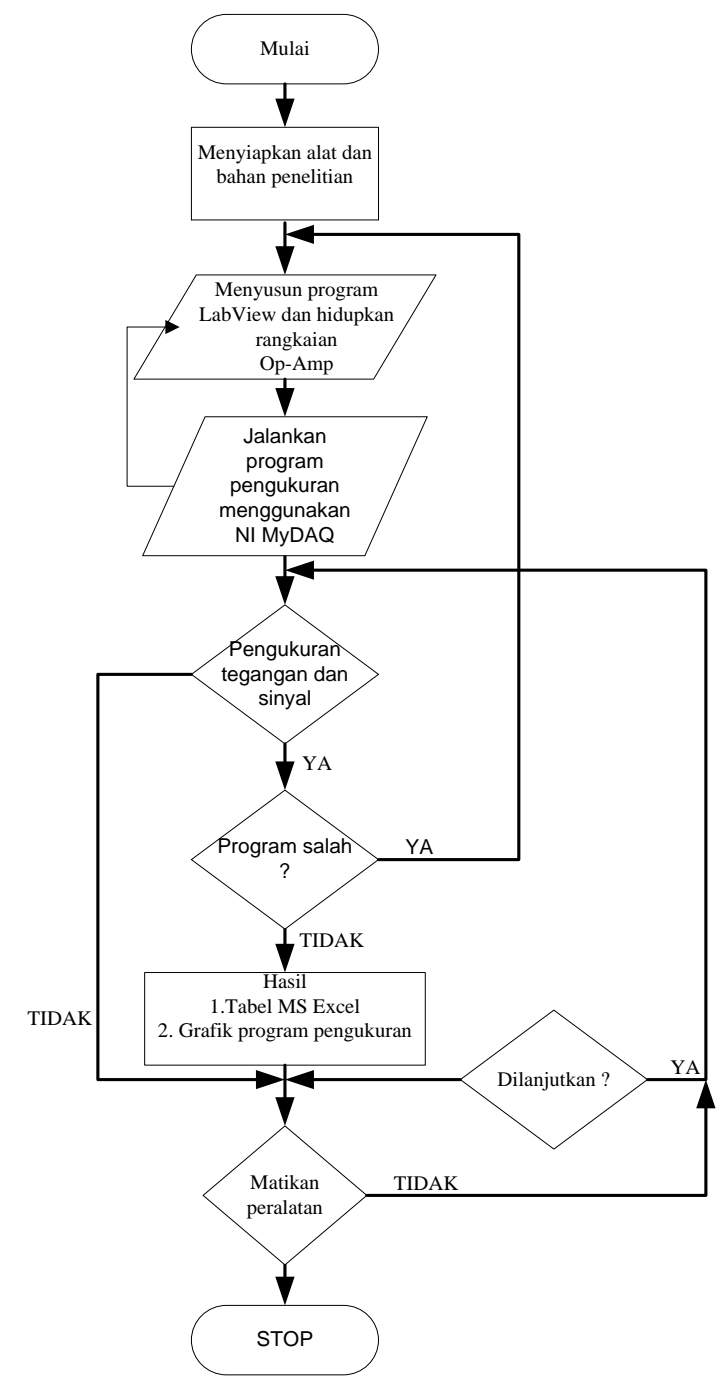

Gambar 8. Flow Chart.

\section{Waktu dan Tempat}

Penelitian dan pengukuran dilakukan pada bulan Januari 2018 dilaksanakan diruang Laboratorium Teknik Elektro, kampus 2. Universitas Pamulang, Tangerang Selatan.

\section{Alat dan Bahan}

Untuk menunjang penelitian dan pengukuran, harus didukung dengan kelengkapan alat yang memadai seperti pada penelitian ini, bahan yang digunakan untuk mendukung proses pengujian dan hasil pengukuran maka diperlukan beberapa peralatan dan bahan antara lain:
1. IC Op-Amp
2. Resistor dan Kapasitor
3. Potensiometer
4. NI My DAQ
5. Multimeter
6. Projecboard
7. Catu daya/tegangan $\mathrm{AC}$ dan $\mathrm{DC}$

\section{Tata kerja}

1. Masukkan rangkai op-amp pada sumber arus ke dalam rangkaian maka sumber arus op-amp sudah dapat digunakan dan disambungkan ke NI My Daq secara manual.

2. Pastikan kembali op-amp yang sudah di rancang dan masuk ke dalam rangkaian kemudian kita mulai menguji rangkaian apakah rangkaian tersebut bekerja dengan baik.

3. Rangkaian penguat op-amp mendapatkan suplay tegangan dari catu daya sebesar yang diinginkan inputannya. Untuk mengukur rangkaian op-amp mendapatkan input dan output dari sensor yang akan memberikan nilai input dan output yang akan di analisa oleh alat NI My Daq dan kemudian hasil penganalisisnya dapat di tampilkan kedalam PC/Komputer dan hasilnya biasa di simpan dalam bentuk file. 


\section{HASIL DAN PEMBAHASAN}

Hasil pengukuran dan pengujian pada rangkaian Op-Amp akan ditampilkan dalam bentuk tabel, sehingga hasilnya lebih mu untuk dilihat dan dianalisa. Seperti tabel yang terlihat di bawah ini, untuk rangkaian Op-Amp penguatan pembalik (inverting)

Tabel 1. Rangkaian Op - Amp Inverting

\begin{tabular}{|c|c|c|c|c|}
\hline Vin & Ri & Rf & Vo & Av \\
\hline 0.5 & $10 \mathrm{~K} \Omega$ & 100 & -3.98 & -5 \\
\hline 0.5 & $22 \mathrm{~K} \Omega$ & 100 & -1.76 & -2.28 \\
\hline 0.5 & $33 \mathrm{~K} \Omega$ & 100 & -1.51 & -1.51 \\
\hline 0.5 & $44 \mathrm{~K} \Omega$ & 100 & -1.12 & -1.13 \\
\hline 0.5 & $100 \mathrm{~K} \Omega$ & 100 & -0.49 & -0.5 \\
\hline
\end{tabular}

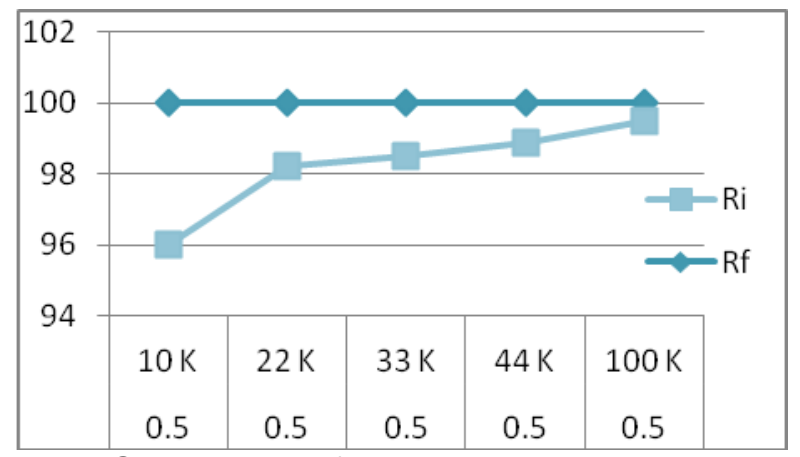

Gambar 9. grafik op-amp inverting

Dari gambar grafik di atas dapat di jelaskan dapat dijelaskan bahwa semakin besar nilai $\mathrm{Ri}$ dengan nilai $\mathrm{Rf}$ yang sama maka akan di hasilkan nilai Vo yang besar.

Penguat pembalik memiliki hambatan R1 sebesar $100 \Omega$ dan R2 sebesar $1 \mathrm{~K} \Omega$. Penguat pembalik tersebut di beri input sebesar $1000 \mu$ Volt. Sehingga dapat di hitung besaran penguatnya dan tegangan outputnya.

$$
A=-\frac{R 2}{R 1}=-\frac{1 K \Omega}{100 \Omega}=-10
$$

$V_{\text {out }}=A \times V_{\text {in }}=-10 \times 1000 \mu$ Volt $=-10 n$ Volt

Penguat pembalik memiliki hambatan R1 sebesar $100 \Omega$. Penguat pembalik tersebut di beri input sebesar $100 \mathrm{~m}$ Volt. Tegangan keluaran dari penguat yang diinginkan 0,2 Volt. Sehinga dapat di hitung berapa besarnya penguat dan hambatan pada $\mathrm{R} 2$.

$$
\begin{gathered}
A=-\frac{V_{\text {out }}}{V_{\text {in }}} \rightarrow \quad A=-\frac{0,2 \text { Volt }}{100 \text { nVolt }} \\
A=-2000 \\
R 2=A \times(-R 1) \\
R 2=-2000 \times(-100 \Omega) \\
R 2=200 \mathrm{k} \Omega
\end{gathered}
$$

Pada pengukuran rangkaian penguat pembalik (inverting) dengan masukan Vin $=0.5$ Volt dan Ri, Rf terdahap Vo dan Av seperti pada gambar di bawah ini:

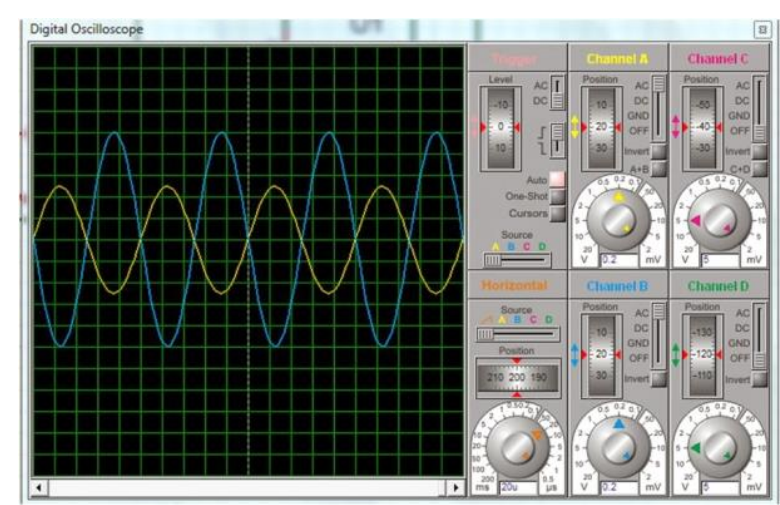

Gambar 10. gelombang rangkaian op-amp inverting pada oscilloscope 


\section{KESIMPULAN.}

Berdasarkan hasil pengukuran dan perhitung tentang rangkaian op-amp dengan beberapa variasi maka dapat disimpulkan sebagai berikut:

1.Rangkaian op-amp penguat inverting merupakan rangkaian penguat pembalik dengan impedansi masukan sangat rendah. Rangkaian penguat inverting akan menerima arus atau tegangan dari tranduser sangat kecil dan akan membangkitkan arus atau tegangan yang lebih besar.

2.penguat op-amp tak-membalik (Non inverting $o p-a m p)$ didesain untuk keperluan penguatan tegangan atau arus yang tinggi tanpa terjadi pembalikan (inversion) isyarat. Rangkain ini dapat digunakan untuk memperkuat isyarat $A C$ maupun DC dengan keluaran yang tetap sefase dengan masukan.

\section{UCAPAN TERIMAKASIH.}

Puji syukur saya ucapkan kepada Alloh yang maha kuasa atas selesainya penelitian ini, pada kesempatan ini penulis ingin mengucapkan terima kasih kepada:

1. Bapak DR.H.Dayat Hidayat, M.M selaku Rektor Universitas Pamulang.

2. Bapak IR.Dadang Kurnia, M.M selaku Dekan Fakultas Teknik Universitas Pamulang.

3. Bapak Syaiful Bakhri, S.T., M.Eng.Sc.,PhD. selaku Ketua Jurusan Teknik Elektro Universitas Pamulang.

4. Ibu Kartika sekar sari, S.T., M.T.Selaku Dosen pembimbing I yang dengan sabar dan senantiasa membimbing dan menyarankan penulisan Penelitian ini.

\section{DAFTAR REFERENSI.}

[1] Frank,D,Petruzella.2001. Elektro Industri.

Penerbit Andi.

Jogjakartahttp://Zone.ni.com/cms/fisika

[2] Holman.J.P.1985.Metode Pngukuran Teknik. Erlangga, Jakarta

[3] Roger L, Sutisna, Prinsif-prinsif Digital, Penerbit Erlangga, Jakarta

[4] M.Zenal Efendi, Transformer Design Of High Frequency

[5] Sutrisno, Listrik Magnet, Bandung 